\title{
Peranan Petugas Kesehatan dan Ketersediaan Sarana Air Bersih dengan Kejadian Diare
}

\author{
Berta Afriani \\ STIKES Al-Ma'arif Baturaja Program Studi DIII Keperawatan \\ Jl. Dr. Mohammad Hatta No 687 B Baturaja \\ Email: bertaafriani@yahoo.co.id
}

\begin{abstract}
ABSTRAK
Data World Health Organization (WHO) menunjukkan bahwa diare masih jadi penyebab nomor satu kematian balita di seluruh dunia. Di Indonesia, diare merupakan pembunuh balita nomor dua setelah ISPA (Infeksi Saluran Pernapasan Akut). UNICEF (badan Perserikatan Bangsa-Bangsa untuk urusan anak) memperkirakan bahwa setiap 30 detik ada satu anak yang meninggal dunia karena diare. Setiap tahun 100.000 balita di Indonesia meninggal karena diare (USAID, 2015). Penelitian ini bertujuan untuk mengetahui korelasi antara kejadian diare dengan peranan petugas kesehatan dan ketersedian sarana air bersih di Kelurahan Talang Jawa Wilayah Kerja UPTD Puskesmas Tanjung Agung tahun 2017. Penelitian menggunakan survey analitik dengan pendekatan cross sectional. Sampel penelitian sebanyak 92 diambil dari populasi dengan menggunakan teknik random sampling. Hasil uji statistik chi-square menunjukkan adanya hubungan yang bermakna antara kejadian diare dengan peran petugas kesehatan dengan $p$ value $=0,000(p<0,05)$ dan ketersedian sarana air bersih dengan $p$ value $=0,022$ ( $p<0$ 05). Hasil penelitian diharapkan dapat menjadi bahan masukan dalam melakukan perencanaan dalam upaya pemberantasan penyakit diare di Kelurahan Talang Jawa Wilayah Kerja UPTD Puskesmas Tanjung Agung.
\end{abstract}

Kata Kunci: Kejadian Diare, Peranan Petugas Kesehatan, Ketersedian Sarana Air Bersih.

\section{THE ROLE OF HEALTH PERSONNEL AND THE AVAILABILITY OF CLEAN WATER FACILITIES WITH DIARRHEA OCCURRENCE}

\begin{abstract}
World Health Organization (WHO) data show that diarrhea is still the number one cause of infant deaths worldwide. In Indonesia, diarrhea is the second most common killer of children under five after ISPA (Acute Respiratory Tract Infection). UNICEF (the United Nations agency on children's affairs) estimates that every 30 seconds one child dies from diarrhea. Every year 100,000 infants in Indonesia die from diarrhea (USAID, 2015). This study aims to determine the correlation between the occurrence of diarrhea with the role of health workers and the availability of clean water facilities in Kelurahan Talang Jawa Working Area UPTD Puskesmas Tanjung Agung 2017. The study used an analytical survey with cross sectional approach. 92 samples are taken from the population using random sampling techniques. The result of chi-square statistic test showed that there was a significant correlation between diarrhea occurrence and the role of health officer with $p$ value $=0,000$ ( $p$ $<0,05)$ and availability of clean water with $p$ value $=0,022(p<0,05)$. The result of the research is expected to be input in planning the eradication of diarrhea disease in Kelurahan Talang Jawa Working Area of UPTD Puskesmas Tanjung Agung.
\end{abstract}

Keywords: Diarrhea Occurrence, Role of Health Officers, Availability of Clean Water Facilities.

How to Cite: Afriani, Berta. (2017). Peranan Petugas Kesehatan dan Ketersediaan Sarana Air Bersih dengan Kejadian Diare. Jurnal Aisyah: Jurnal Ilmu Kesehatan. 2 (2), 117 - 122. 


\section{PENDAHULUAN}

Diare adalah buang air besar (defekasi) dengan tinja berbentuk cair atau setengah cair (setengah padat), kandungan air tinja lebih banyak dari biasanya lebih dari 200 gram atau 200ml / 24 jam. Definisi lain memakai kriteria frekuensi, yaitu buang air besar encer lebih dari $3 \mathrm{kali} /$ hari. Buang air besar encer tersebut dapat disertai lendir dan darah (Syahfarini, 2013).

Menurut WHO (2010) secara klinis diare didefinisikan sebagai bertambahnya defekasi (buang air besar) lebih dari biasanya/lebih dari tiga kali sehari, disertai dengan perubahan konsisten tinja (menjadi cair) dengan atau tanpa darah (Ineke, 2013).

Penyakit diare hingga saat ini masih menjadi masalah di Indonesia. Padahal berbagai upaya penanganan, baik secara medik maupun upaya perubahan tingkah laku dengan melakukan pendidikan kesehatan terus dilakukan. Namun, upayaupaya tersebut belum memberikan hasil yang menggembirakan. Setiap tahun penyakit ini masih menduduki peringkat atas, khususnya di daerah-daerah miskin (Kurniawan, 2014).

Menurut data World Health Organization (WHO), diare masih jadi penyebab nomor satu kematian balita di seluruh dunia. Di Indonesia, diare adalah pembunuh balita nomor dua setelah ISPA (Infeksi Saluran Pernapasan Akut). Sementara UNICEF (Badan Perserikatan Bangsa-Bangsa untuk urusan anak) memperkirakan bahwa, setiap 30 detik ada satu anak yang meninggal dunia karena diare. Di Indonesia, setiap tahun 100.000 balita meninggal karena diare (USAID, 2015).

Penyakit Diare merupakan penyakit endemis di Indonesia dan juga merupakan penyakit potensial KLB yang sering disertai dengan kematian. Menurut hasil Riskesdas 2007, Diare merupakan penyebab kematian nomor satu pada bayi $(31,4 \%)$ dan pada balita $(25,2 \%)$, sedangkan pada golongan semua umur merupakan penyebab kematian yang ke empat (13,2\%). Menurut Riskesdas 2013, insiden diare berdasarkan gejala pada seluruh kelompok umur sebesar 3,5\% (kisaran menurut provinsi 1,6\%-6,3\%) dan insiden diare pada balita sebesar 6,7\% (kisaran provinsi 3,3\%-10,2\%). Sedangkan period prevalence diare pada seluruh kelompok umur berdasarkan gejala sebesar $7 \%$ dan pada balita sebesar 10,2\% (Kemenkes RI, 2014).

Berdasar metaanalisis di seluruh dunia, setiap anak minimal mengalami diare satu kali setiap tahun. Dari setiap lima pasien anak yang datang karena diare, satu di antaranya akibat rotavirus. Kemudian, dari 60 anak yang dirawat di rumah sakit akibat diare satu di antaranya juga karena rotavirus (Medicastore. 2015)

Jumlah penderita diare turun secara signifikan dari tahun 2012 sebanyak 1.654 kasus dibandingkan tahun 2013 sebanyak 646 kasus. Kejadian Luar Biasa diare pada tahun 2013 terjadi di 6 provinsi dengan penderita terbanyak terjadi di Jawa Tengah yang mencapai 294 kasus. Sedangkan angka kematian (CFR) akibat KLB diare tertinggi terjadi di Sumatera Utara yaitu sebesar 11,76\% (Kemenkes RI, 2014).

Jumlah kasus diare di Sumatera Selatan pada tahun 2011 sebanyak 196.785 kasus dan pada tahun 2012 meningkat menjadi 247.566 kasus (Dinkes Sumsel, 2012). Berdasarkan data hasil laporan SP2 Diare di Dinas Kesehatan Kabupaten Ogan Komering Ulu (OKU) tahun 2012 terdapat 67.531 balita dengan diare sebanyak 7.408 kasus (10,97\%), pada tahun 2013 terdapat 63.439 balita dengan diare $6.652(10,49 \%)$ kasus diare pada anak dan pada tahun 2014 terdapat 68.577 balita dengan diare sebanyak $7820(11,40 \%)$ kasus diare pada anak (Dinkes OKU, 2015).

Berdasarkan data dari UPTD Puskesmas Tanjung Agung, pada tahun 2014 jumlah yang menderita diare sebanyak 1.164 kasus, naik menjadi 1.030 kasus pada tahun 2015 dan pada tahun 2016 turun menjadi 


\section{Jurnal Aisyah: Jurnal Ilmu Kesehatan 2 (2) 2017, - 119}

Berta Afriani

sebanyak 862 kasus. Berdasarkan data diatas penulis tertarik untuk meneliti hubungan antara peranan petugas kesehatan dan ketersedian sarana air bersih dengan kejadian diare.

\section{METODE PENELITIAN}

Jenis penelitian yang digunakan adalah survey analitik dengan pendekatan cross sectional yang bertujuan untuk menganalisa faktor-faktor yang berhubu-ngan dengan Kejadian diare. Survei cross sectional yaitu menguji variabel indepen-den (peranan petugas kesehatan dan ketersediaan sarana air bersih,) dengan variabel dependen (kejadian diare) dimana data yang didapatkan sekaligus pada saat bersamaan (Notoatmodjo, 2010).

Populasi dalam penelitian ini adalah Kepala Keluarga yang berada di Kelurahan Talang Jawa Wilayah Kerja UPTD Puskesmas Tanjung Agung Kecamatan Baturaja Barat Kabupaten Ogan Komering Ulu Sumatera Selatan sebanyak 2.176 KK. Sampel adalah sebagaian atau wakil populasi yang diteliti
(Arikunto, 2010), dalam penentuan sampel menggunakan tehnik Random Sampling, dalam penentuan sampel menggunakan rumus dari (Iwan Ariawan, 1998) dalam Notoatmodjo (2010) sebanyak 92 Kepala Keluarga. Lokasi penelitian ini dilakukan di Kelurahan Talang Jawa Wilayah Kerja UPTD Puskesmas Tanjung Agung Kecamatan Baturaja Barat Kabupaten Ogan Komering Ulu pada periode September November Tahun 2017. Analisa data menggunakan analisa data univariat dan bivariat. Analisa dilakukan dengan tabulasi silang dan uji statistik dengan menggunakan rumus chi square dengan derajat kepercayaan $95 \%$ bila $p$ value $\leq$ 0,05 menunjukkan hubungan bermakna dan tidak bermakna jika $p$ value $>0,05$.

\section{HASIL DAN PEMBAHASAN}

Analisa univariat dilakukan untuk mengetahui distribusi frekuensi dan persentase dari variabel independen dengan variabel dependent.

Tabel 1. Distribusi Frekuensi

\begin{tabular}{lcc}
\multicolumn{1}{c}{ Variabel } & Frekuensi & Persentase \\
\hline $\begin{array}{l}\text { Kejadian Diare } \\
\text { - Tidak Diare }\end{array}$ & 39 & 42,4 \\
- Diare & 53 & 57,6 \\
Peranan Petugas Kesehatan & & \\
$\quad$ - Baik & 31 & 33,7 \\
- Tidak Baik & 61 & 66,3 \\
Ketersedian sarana air bersih & & \\
- Tersedia & 45 & 48,9 \\
- Tidak Tersedia & 47 & 51,1 \\
\hline
\end{tabular}

Table 1. menunjukkan bahwa dari 92 kepala keluarga yang didalam keluarganya tidak mengalami kejadian diare sebanyak $39(42,4 \%)$ dan yang diare sebanyak 53(57, 6\%). Data yang menunjukkan Peranan petugas kesehatan baik sebanyak 31 (33, $7 \%$ ) dan yang tidak baik sebanyak 61 (66, $3 \%$ ). Sarana air bersih yang tersedia sebanyak $45(48,9 \%)$ dan yang tidak tersedia sebanyak $47(51,1 \%)$.
Analisa bivariat dilakukan untuk mengetahui hubungan antara variabel independen dengan variabel dependen dengan batas kemaknaan $p$ value $\leq 0,05$ artinya ada hubungan yang bermakna (signifikan) dan bila $p$ value $>0,05$ maka hubungan tidak bermakna, uji statistik digunakan adalah uji chi-square. 
Jurnal Aisyah: Jurnal Ilmu Kesehatan 2 (2) 2017, - 120

Berta Afriani

Tabel 2. Hasil Analisis Hubungan Antara Kejadian Diare dengan Peran Petugas Kesehatan dan Ketersediaan Sarana Air Bersih

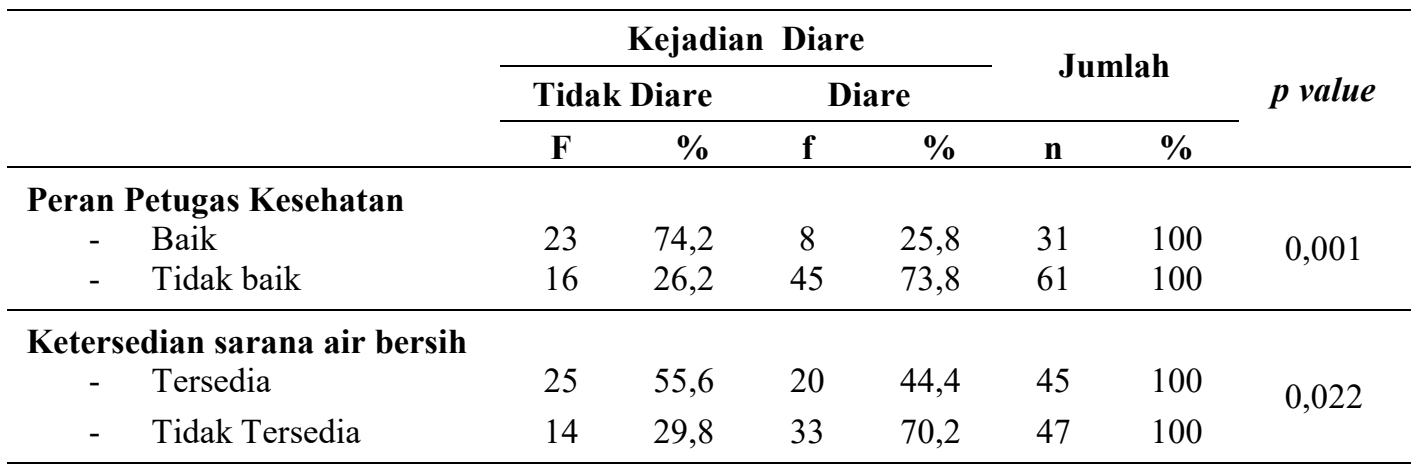

Berdasarkan Tabel 2 diatas menunjukan bahwa dari 92 kepala keluarga yang mengatakan peranan petugas kesehatan baik yang tidak mengalami kejadian diare sebanyak $23(74,2 \%)$ dan yang mengatakan peranan petugas kesehatan baik yang mengalami kejadian diare sebanyak 8 $(25,8 \%)$, sedangkan kepala keluarga yang mengatakan peranan petugas kesehatan tidak baik yang tidak mengalami kejadian diare sebanyak $16 \quad(26,2 \%)$ dan yang mengatakan peranan petugas kesehatan tidak baik yang mengalami kejadian diare sebanyak 45 (73,8\%). Hasil uji statistik chi-square menunjukkan $p$ value sebesar $0,001(\mathrm{p}<0,05)$, sehingga dapat disimpulkan bahwa terdapat hubungan yang bermakna antara Peran Petugas Kesehatan terhadap kejadian diare di Kelurahan Talang Jawa Wilayah Kerja UPTD Puskesmas Tanjung Agung.

Hasil pengukuran pada 92 kepala keluarga yang memiliki sarana air bersih namun tidak mengalami kejadian diare sebanyak $25(55,6 \%)$ dan yang memiliki sarana air bersih namun mengalami diare sebanyak 20 $(44,4 \%)$. Kepala keluarga yang tidak memiliki sarana air bersih dan tidak mengalami kejadian diare sebanyak 14 $(29,8 \%)$, sedangkan yang tidak memiliki sarana air bersih namun mengalami diare sebanyak $33(70,2 \%)$.

Hasil uji statistik chi-square didapat $p$ value sebesar $0,022(\mathrm{p}<0,05)$, sehingga hasil tersebut menunjukan adanya hubungan yang bermakna antara ketersedian sarana air bersih dengan kejadian diare di Kelurahan Talang Jawa Wilayah Kerja UPTD Puskesmas Tanjung Agung.

Hasil penelitian peran petugas kesehatan dengan kejadian diare ini sejalan dengan hasil penelitian yang dilakukan oleh Yanto (2012) menunjukan bahwa proporsi responden yang mengatakan peranan petugas kesehatan kurang baik yang dinyatakan sakit diare $65,7 \quad \%$ dan responden yang menatakan peranan petugas kesehatan baik yang dinyatakan sakit Diare $44,8 \%$. Hasil uji statistik chi-square didapat $p$ value sebesar $0,007(\mathrm{p}<0,005)$ maka hasil tersebut menunjukan adanya hubungan yang bermakna antara peranan petugas kesehatan dengan kejadian Diare.

Peran Petugas kesehatan dalam melakukan pencegahan penyakit diare yaitu dengan melakukan penyuluhan tentang penyakit diare, melakukan penyelidikan setiap muncul kasus diare, himbauan atau ajakan untuk melakukan kebersihan lingkungan, dan memusyawarahkan kasus diare. Tetapi kurang efektif dikarenakan luas lingkungan puskesmas tanjung agung sangat luas dan kurangnya petugas kesehatan sehingga peran petugas tidak maksimal.

Hasil penelitian diharapkan dapat meningkatkan peranan petugas dalam memberikan penyuluhan dengan cara memberikan petunjuk bila didalam keluarga ada yang menderita diare agar secepatnya diberi minum yang banyak (dengan menjelaskan perlunya minum banyak saat 


\section{Jurnal Aisyah: Jurnal Ilmu Kesehatan 2 (2) 2017, - 121}

Berta Afriani

diare) dan lebih baik dengan oralit / jika tidak ada dapat dengan larutan gula dan garam. Namun jika anak muntah lebih sering dan/atau buang air besar terus sehingga pemberian oralit tidak dapat menolong supaya segera dibawa berobat kepelayanan kesehatan agar tidak terlambat untuk mencegah timbulnya keadaan dehidrasi berat.

Begitupun hasil penelitian sarana ketersediaan air bersih dengan kejadian diare ini sejalan dengan hasil penelitian yang dilakukan oleh Mafazah (2013) di wilayah kerja Puskesmas Purwoharjo Kabupaten Pemalang terhadap 63 responden didapatkan analisis dengan menggunakan uji chi square, diperoleh nilai $p=0,001(\mathrm{p}<0,05)$ sehingga Ho ditolak. Hal ini berarti bahwa ada hubungan antara ketersediaan sarana air bersih dengan kejadian diare pada balita.

Tujuan penyediaan air bersih adalah membantu penyediaan yang memenuhi syarat kesehatan dan pengawasan kualitas air bagi seluruh masyarakat baik yang tinggal diperkotaan maupun dipedesaan serta meningkatkan kemampuan masyarakat untuk penyediaan dan pemanfaatan air bersih. Air bersih yang digunakan selain harus mencukupi dalam arti kuantitas untuk kehidupan sehari-hari juga harus memenuhi persyaratan kualitas fisik, kimia, mikrobiologi dan radioaktif.

Hasil penelitian menunjukkan bahwa sebagian besar keluarga di Kelurahan Talang Jawa Wilayah Kerja UPTD Puskesmas Tanjung Agung menggunakan sumber air bersih dari sumur dan PDAM. Namun, walaupun sumur dan PDAM yang sudah digunakan oleh masyarakat/keluarga memenuhi syarat kesehatan dengan cara menutup sumur, tetapi air pembuangan limbah masih berdekatan dengan sumur/sumber air bersih tersebut dan kurangnya masyarakat menjaga kebersihan disekitar/sumber air bersih.

\section{KESIMPULAN DAN SARAN}

Berdasarkan penelitian yang dilakukan terhadap 92 responden Kepala keluarga Kelurahan Talang Jawa Wilayah Kerja UPTD Puskesmas Tanjung Agung maka dapat ambil kesimpulan bahwa terdapat korelasi yang bermakna antara kejadian diare dengan Peran Petugas Kesehatan dan sarana ketersediaan air bersih dengan $p$ value $<0,05$ menggunakan uji statistik chi-square.

Saran yang dapat disampaikan kepada institusi kesehatan berdasarkan hasil penelitian adalah perlu untuk meningkatkan penyuluhan untuk meningkatkan kewaspadaan masyarakat terhadap bahaya penyakit diare. Untuk masyarakat harus selalu waspada terhadap kejadian diare dan sebaiknya tetap antusias untuk mengikuti penyuluhan kesehatan, baik dari puskesmas maupun dari sumber lain. Agar lebih memaksimalkan lagi penyuluhan tentang diare dapat dilakukan dengan menambah petugas agar penyuluhan dapat lebih efektif mengingat luasnya wilayah kerja UPTD Puskesmas Tanjung Agung sehingga warga masyarakat bisa mendapatkan penyuluhan kesehatan khususnya penyakit diare secara merata. 


\section{DAFTAR PUSTAKA}

Arikunto, S. (2010). Prosedur penelitian: Suatu Pendekatan Praktik. (Edisi Revisi). Jakarta: Rineka Cipta.

Anwar. (2011). Panduan Prasarana Air Bersih.

Armanji. (2010). Hubungan Sanitasi Lingkungan Dengan Kejadian Diare Di Wilayah Kerja Puskesmas BaraBaraya Makassar.

Dinkes OKU. (2015). Profil Kesehatan Kabupaten OKU.

Ineke. (2013). Makalah. diare pada anak. http://inekehr.blogspot.com/2013/ 06/makalah-diare-pada-anak.html.

Kemenkes RI. (2014). Profil Kesehatan Indonesia. Jakarta: Kemenkes RI.

Kurniawan, Irfan. (2014). Makalah Keperawatan, Satuan Acara Penyuluhan, dan Laporan Pendahuluan. http://kumpulanmakalah-keperawatanku.blogspot. com/2014/01/ makalah-diare.html.

Kurniawan. (2015). Asuhan keperawatan pada anak dengan diare.

Listianingsih, dkk. (2014). Hubungan Pengetahuan Ibu Dengan Sikap Dalam Penanganan Awal Diare Pada Anak Prasekolah Di Rw 12 Desa Jaya Mekar Padalarang.

Lestari. (2013). Dehidrasi. http://rainyday051.blogspot.com/2013 /02/dehidrasi.html.

Notoatmodjo, S. (2010). Metodologi Penelitian Kesehatan. Jakarta: Rineka Cipta.

Rianto. (2015). Sistim penyediaan air bersih. airbersih-amdk.blogspot.com /.../sistem-penyediaan-air-bersih.html
Syahfarini. (2013). Penyakit Diare. http://goodclass12kpra.blogspot.com/ 2013/12/penyakit-diare-ifa.

Saputra. (2015). 19 Penyebab Diare dan Cara mengobatinya.

USAID. (2015). USAID dan Nestlé Indonesia Bekerja Sama Tingkatkan Akses terhadap Air dan Sanitasi. 